\title{
MINERALOGIA DE UM ARGISSOLO VERMELHO-AMARELO EUTRÓFICO E DE UM PLANOSSOLO HÁPLICO EUTRÓFICO SOLÓDICO NUMA TOPOSSEQÜÊ NCIA DE GNAISSE NO SERTÃO CENTRAL DO CEARÁ(1)
}

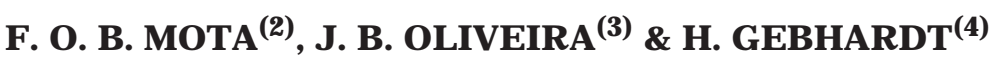

\begin{abstract}
RESUMO
Propriedades morfológicas, físi cas e químicas, mi neralogia e transformações mineralógicas foram investigadas num Argissolo Vermelho - Amarelo eutrófico (bem drenado) e num Planossolo Háplico eutrófico solódico (imperfeitamente drenado), originados de gnaisse, numa toposseqüência no Sertão Central do Ceará. $O$ trabalho teve o propósito de avaliar a influência da posição dos solos na pai sagem (drenagem interna) e na diversificação de suas propriedades, bem como estudar a ação de processos superficiais de transporte e deposição na homogeneidade do material originário. A areia e o silte grosso foram analisados por mi croscopia de polarização e contraste de fase, e o silte fino e a argila, por difração de raios-X. A microscopia eletrônica de varredura foi também uti lizada com o objetivo de fornecer informações complementares sobre as alterações mineralógicas ocorridas. As frações areia e silte grosso apresentaram no Argissolo Vermelho-Amarelo eutrófico (PVAe) grande teor de biotita e no Planossolo Háplico Eutrófico solódico (SXen), biotita e hornblenda com considerável redução dos horizontes inferiores em direção à superfície. Quartzo e plagioclásios foram também encontrados nessas frações em ambos os solos. Na fração argila do PVAe, dominam caulinita e vermiculita, ocorrendo também quartzo, e no silte fino, a caulinita édomi nante com ocorrência de teores variáveis de biotita, plagioclásios e quartzo. No Sxen, a fração mais fina é domi nada por
\end{abstract}

(1) Parte da Tese de Doutorado do primeiro autor, apresentada à Escola Superior de Agricultura "Luiz de Queiroz" - ESALQ/USP. Recebido para publicação em setembro de 1997 e aprovado em abril de 2002.

(2) Professor do Departamento de Ciência do Solo da Universidade Federal do Ceará - UFCe. Campus do Pici - Bloco 807, CEP 60455760 Fortaleza (CE). E-mail: ocian@ufc.br

(3) Professor do Departamento de Água e Solo, Faculdade de Engenharia Agrícola, Universidade de Campinas - UNICAMP. Cidade Universitária Zeferino Vaz - Barão Geraldo, CEP 13083-970 Campinas (SP). Bolsista do CNPq. E-mail: bertoldo@barao.iac.br

(4) Professor Universität Oldenburg, Fachbereich 7, Biologie, Postfach 2503, 26111 Oldenburg - Deutschland. 
caulinita e montmorilonita, ocorrendo ainda, em alguns horizontes, quartzo e um mineral interestratificado regular de $2,4 \mathrm{~nm}$ (vermiculita + mica). No silte fino, além da ocorrência dos minerais primários supracitados, verificou-se a presença de caulinita, ilita, vermiculita, montmorilonita e do mineral interestratificado, com teores variáveis de horizonte para horizonte. A drenagem interna de cada solo propiciou condições diferentes para as transformações dos minerais biotita, hornblenda e plagioclásios, com os dois primeiros, inicialmente, se alterando em argilomineral 2:1, e o segundo diretamente em caulinita. E m ambos os perfis, o teor de argila no B textural resultou, essencialmente, do intemperismo dos minerais primários da rocha subjacente.

Termos de indexação: mineralogia, transformações mineralógicas, drenagem interna, região semi-árida, Brasil.

\title{
SUMMARY: MINERALOGY OF A RED YELLOW ARGISOL AND A SOLODIC PLANOSOL IN A GNEISS TOPOSSEQUENCE OF THE CENTRAL SEMIARID REGION OF CEARÁ STATE, BRAZIL
}

\begin{abstract}
Morphological, physical, chemical and mineralogical properties, as well as the weathering processes werestudied in a Red Yellow Argisol (AridicKandiustalf) (well drained) and a Solodic Planosol (Aridic Haplustalf) (partially drained), developed from gnaisses, in a topossequence of the central semiarid region of Ceará State, Brazil. The study had the purpose of investigating theinfluence of soil locations in thelandscape (internal drainage) and on the diversification of soil properties, as well as to study processes of surfacetransport and deposition on thehomogenous parent material. Coarsesand and silt werestudied using polarized microscopy and phase contrast, while fine silt and clay were analyzed by X-ray diffraction. Additional information on mineralogical alterations were obtained using a scanning electron mi croscope Sand and coarsesilt presented largecontents of biotitein the Red Yellow Argisol (PVAe) and biotite plus hornblendein theSolodic Planosol (SXen), with a considerabl e decrease from lower horizons towards the surface. In both soils, quartz and plagi oclases were also found within these fractions. Dominant clay minerals of the PVAe were kaoliniteand vermiculitein theclay fraction with occurrence of quartz, and kaol inite in thefinesilt with variablecontents of biotite, plagioclases and quartz. On theother hand, kaolinite and montmorillonite are dominant in the SXen, but quartz and a regular interstratified mineral (vermi culite + mica) wereal so observed in somehorizons. In thefine silt, together with the abovementioned primary minerals, kaolinite, illite, vermiculite, montmorillonite and theregular interstratified mineral wereobserved in variable contents for every horizon. The internal drainage of both soils promoted different conditions for the transformations of biotite, hornblendeand plagi oclases: the first two initially form 2:1 clay minerals, whilepl agioclases changedirectly tokaol inite. Clay contents in theargillic horizon in both profiles wereessentially a result of weather ed primary mi nerals from thesubjacent rock.
\end{abstract}

Indexterms: mineralogy, mineralogical transformations, internal drainage, semiarid region, Brazil.

\section{INTRODUÇÃO}

Na região do Sertão Central do estado do Ceará, os Argissolos Vermel ho-Amarel os eutróficos (PVAe) e os Planossol os Hápli cos eutróficos solódicos (SXen) são degrande importância agronômica para a região, seja pela expressão geográfica, seja pelo uso agrícola a que são submetidos.

Nas descrições gerais desses solos, na região fisiográfica supracitada, eles estão associados com rochas cristalinas referidas ao Pré-Cambriano, principalmente a gnaisses e migmatitos, sendo, na maioria dos casos, autóctones ou pseudo-autóctones (Brasil, 1973).

A mineralogia, as transformações mineralógicas ea pedogênese no dima tropical semi-árido cearense carecem de muitos esclarecimentos, necessitando de pesquisas que possam elucidar tais processos. Por outrolado, informações mineralógi cas sobre os sol os da região fisiográfica ora estudada são bastante 
escassas, restringindo-se praticamente àquelas contidas no Levantamento Exploratório-Reconhecimento de Solos do Estado do Ceará (Brasil, 1973) e poucos outros em áreas mais específicas (Moreira, 1979).

Associações de PVAe e SXen no Sertão Central do Ceará são típicas da região, com os Argissolos Vermel ho-Amarel os ocupando posições de topo e encosta em ambiente de boa drenagem, e os Planossolos Háplicos eutróficos solódicos as partes mais baixas do relevo, em ambiente de drenagem deficiente (Figura 1 ).

A influência da drenagem interna do solo na mineralogia, gênese etransformações mineralógicas de seus minerais secundários e, ou, primários é amplamente relatada na literatura. Os fatores ambientais, tais como: o clima e seus componentes, a drenagem e os fatores bióticos, todos el es intimamente relacionados, têm influência decisiva na formação dos argilominerais do solo. Assim, não é muito freqüente encontrar caulinita em solos de regiões áridas muito quentes. A gênese de argilominerais a partir de hornblendas depende das condições de drenagem e precipitação. A tendência é a formação de montmorilonita ou clorita nas primeiras etapas (Besoain, 1985).

Cass \& J ohnston (1985), trabal hando com solos australianos, em região semi-árida, estabel eceram uma correlação entre a mineral ogia da fração argila e problemas intrínsecos dos solos, tais como: drenagem interna, densidade edispersão das argilas. Os sol os pobremente drenados tinham tendência de ser dominados por minerais do grupo das esmectitas, enquanto solos dispersivos e compactados tinham uma composição mineralógica mista composta de esmectita, mica e caulinita. Por sua vez, os sol os de drenagem livre apresentaram-se essencialmente cauliníticos.

Demattêet al . (1991) observaram a influência da drenagem interna do solo nos ganhos e perdas de elementos no processo de intemperismo; demaneira geral, as perdas foram mais intensas nos locais mais bem drenados do solo. Demattê \& Marconi (1991) também verificaram a maior concentração de montmorilonita em solos de drenagem imperfeita, apesar deser a região subtropical úmida. Em solos pobremente drenados, quando comparados a outros bem drenados, a lixiviação e a velocidade de meteorização foram reduzidas, explicando seus maiores teores de silte, bases trocáveis, argilominerais 2:1 e CTC (Demattê et al., 1991).

Luz et al. (1992), pesquisando uma toposseqüência de solos Brunos Não-Cálcicos e Planossolo Solódico no semi-árido pernambucano, observaram queas principais diferenças entre esses sol os estavam subordinadas ao condicionamento de suas posições ao longo do relevo, que exerce influência na drenagem e nos processos superficiais detransporte e deposição. Transformações de micas (biotitas) em vermiculitas trioctaédricas e estas em esmectitas são processos atuantes nesses solos. Verificaram, ainda, uma diminuição de esmectita e um aumento de caulinita na direção dos horizontes superficiais.

Assim sendo, o objetivo deste trabalho foi pesquisar a influência das condições de drenagem interna do solo na mineralogia de um Argissolo Vermelho-Amarelo eutrófico e de um Planossolo Háplico eutrófico sol ódico, localizados em uma toposseqüência e originados de gnaisse.

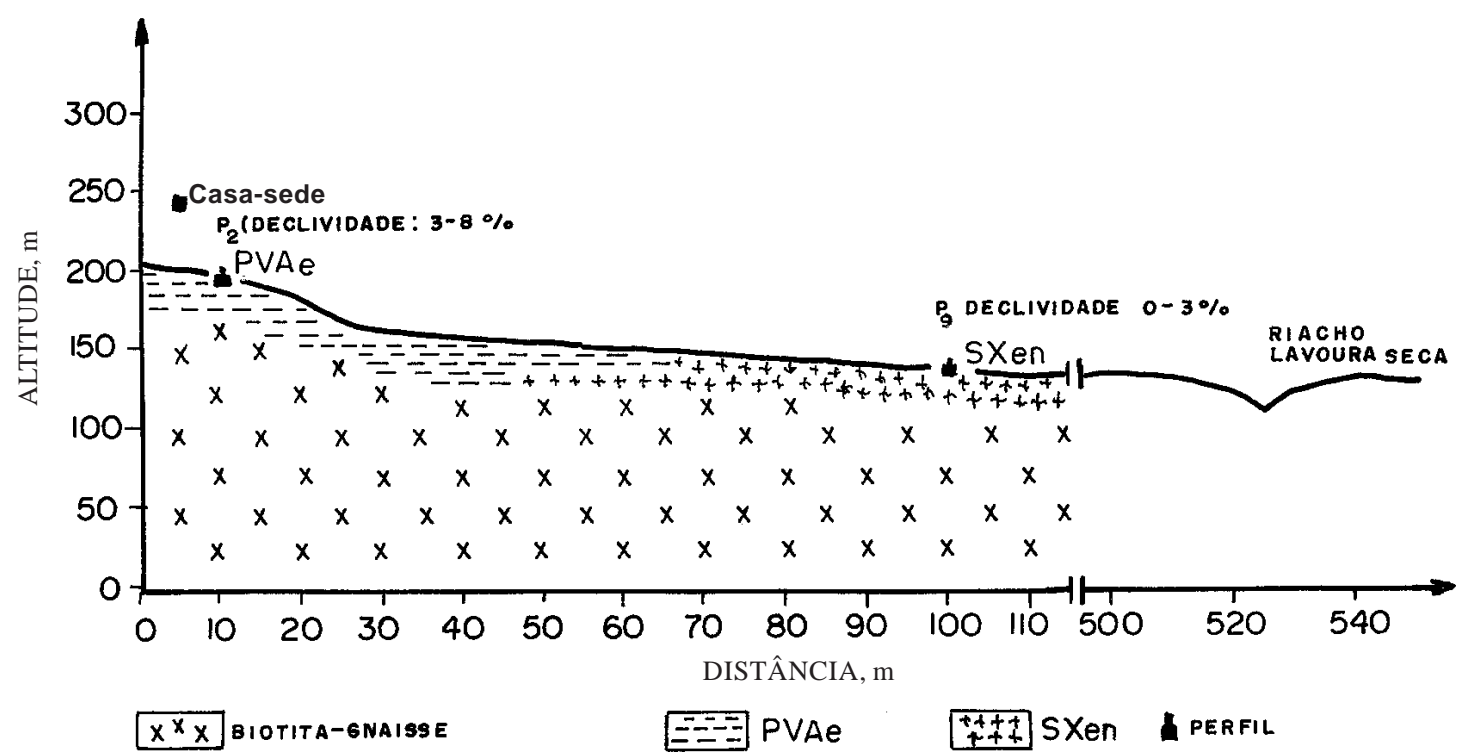

Figura 1. Perfil geológico e topográfico com a localização dos pedons amostrados: perfil 2 (PVAe) e perfil 9 (SXen). 


\section{MATERIAL E MÉTODOS}

A toposseqüência em estudo está localizada na Fazenda Lavoura Seca, pertencenteà U niversidade Federal do Ceará, no município de Quixadá, na zona fisiográfica do Sertão Central (Brasil, 1973), onde foram descritos e amostrados dois perfis de solos de acordo com Lemos \& Santos (1984), utilizando-se a nomenclatura de horizontes atualmente em vigor (EMBRAPA, 1988). A classificação dos sol os foi feita de acordo com o Sistema Brasileiro de Classificação de Solos (EMBRAPA, 1999) e também conforme SOIL SURVEY STAFF (1992). O clima da área é tipicamente semi-árido (tropical quente de seca acentuada), com temperatura do mês mais frio superior a $18^{\circ} \mathrm{C}$ e 7 a 8 meses secos (Bsw'h, na classificação de Köeppen, e 4aTh, na classificação de Gaussen). A precipitação média anual está em torno de $800 \mathrm{~mm}$ e a vegetação regional é do tipo caatinga hiperxerófila (Brasil, 1973). Litologicamente, estão associados com gnaisses do Pré-Cambriano Indiviso e, geomorfologicamente, com a Superfície de Aplainamento Sertaneja, desenvolvida em decorrência de processos de pediplanação influenciados por clima seco (Souza, 1975).

As análises de alguns atributos físicos (análise granulométrica e argila dispersa em água) e químicos (pH em água, complexo sortivo, CTC, Ki) para caracterização e classificação dos solos foram feitas no laboratório de solos da Universidade Federal do Ceará, seguindo o método usado pela EMBRAPA (1979). Na análise granulométrica, a fração terra fina $(<2 \mathrm{~mm}$ ) foi dispersada com $\mathrm{NaOH}$ $1 \mathrm{mo} \mathrm{L}^{-1}$. A areia foi separada por peneiramento, enquanto o fracionamento do silte e a separação deste da argila foram feitos por sedimentação.

A identificação dos minerais presentes na areia e no silte grosso foi feita por microscopia ótica de polarização e contraste defase, em preparados destas frações, segundo Gebhardt et al. (1967) eTroger (1969). A quantificação das fases minerais, neste caso, foi efetuada por contagem de grãos, com a estimativa de cada espécie mineral feita em \% de peso da terra fina. Para identificar, de forma precisa, as espécies minerais, foram utilizados ainda difratogramas do pó das partículas; para os feldspatos, usou-setambém a técnica de coloração com hexacobaltonitrito de sódio. As frações silte fino e argila foram anal isadas por difratometria de raios-X, em amostras orientadas ena forma de pó, após el iminação da matéria orgânica edos óxi dos de ferro segundoJ ackson (1969), seguida da saturação com potássio e magnésio. Nos tratamentos com potássio, os difratogramas foram obtidos em amostras submetidas à temperatura ambiente e após aquecidas a 350 e $550^{\circ} \mathrm{C}$ por duas horas. Os tratamentos com magnésio foram analisados à temperatura ambiente e após adição de etilenoglicol. Para tanto, utilizou-se um equipamento derai os-X Philips micro 1130, dotado detubo decobre efiltro de níquel.
Para obter informações complementares das transformações mineralógicas ocorridas, frações granulométricas sel ecionadas dos dois perfis foram ainda examinadas por microscopia eletrônica de varredura, utilizando-se equipamento REM Zeiss 940.

A avaliação semiquantitativa dos minerais das frações mais finas foi obtida por meio do cál culo das áreas dos pi cos dos difratogramas seguindo o método de J ohns et al. (1954). A identificação qualitativa foi feita segundo Brindley (1955), J ackson (1969) e Brown (1961).

\section{RESULTADOS E DISCUSSÃO}

\section{Atributos morfológicos físicos e químicos}

A profundidade do "solum" varia de $205 \mathrm{~cm}$, no PVAe, a $79 \mathrm{~cm}$, no SXen, embora o PVAe apresente maior erosão, já que tem o horizonte superficial parcialmente truncado. A diferenciação de cores entre os dois perfis resulta de suas posições na paisagem, condicionadas por suas drenagens internas. A cor avermel hada no horizonte Bt do Argissolo, de boa drenagem, é substituída por uma coloração variegada no Planossolo, que tem drenagem imperfeita elocal iza-se na zona de maior acumulação deágua da toposseqüência. A estrutura em blocos é rel ativamente bem desenvol vida ao longo de toda a profundidade no PVAe e nos horizontes 2Btn e 2BCn do SXen. A presença de superfícies brilhantes e cerosas (cerosidade), formando revestimentos nas unidades estruturais do Bt, mostra-seevidenteno PVAe, porém nãofoi detectada no mesmo horizonte do SXen (Quadro 1).

O Argissolo de textura média não mostra acentuado aumento de argila em profundidade (relaçãotextural =1,5), mas a erosãolaminar severa no horizonte superficial e a presença de cerosidade detectada no campo permitem qualificar o horizonte $B$ desse solo como B textural. O Planossolo com textura arenosa/argilosa tem uma relação textural el evada, da ordem de 6,5, concordando com os resultados obtidos em outros perfis dessa classe (Camargo et al., 1987 e Oliveira et al., 1992). A relação silte/argila maior em quase todos os horizontes do SXen em relação ao PVAe traduz, de certa forma, maior intemperização do segundo solo quando comparado ao primeiro (Quadro 2).

O compl exosortivo, os val ores deKi eos principais atributos quími cos também diferem nos dois perfis, tendo forte influência da posição no relevo. O Argissolo apresenta argila de atividade baixa, enquanto o Planossol o tem argila de atividade alta e saturação por bases mais el evada, embora ambos os solos mostrem caráter eutrófico, com as bases trocáveis sendo supridas pelas grandes quantidades 
Quadro 1. Atributos morfológicos dos perfis de Argissolo Vermelho-Amarelo eutrófico (PVAe) e de Planossolo Háplico eutrófico solódico (SXen)

\begin{tabular}{|c|c|c|c|c|c|c|c|c|c|}
\hline Solo & Horizonte & Profundidade & Cor $(1)$ & Textura(2) & Estrutura(3) & Seco & $\begin{array}{l}\text { Consistência } \\
\text { úmido }\end{array}$ & Molhado(4) & Cerosidade $^{(5)}$ \\
\hline & & $\mathrm{cm}$ & & & & & & & \\
\hline \multirow[t]{6}{*}{ PVAe } & A & $0-12$ & $5 Y R 4 / 3$ & a. $f$ & b. $s$ & - & friável & $n p$ e $n p$ & - \\
\hline & $A B$ & $12-43$ & $5 Y R 4 / 4$ & f. a & b. $\mathrm{s}$ & - & friável & Ip e Ip & - \\
\hline & BA & $43-74$ & $5 Y R 4 / 4$ & f. $a$ & b. $\mathrm{s}$ & - & friável & Ip e Ip & - \\
\hline & Bt1 & $74-119$ & 5YR4/6 & f. a. a & b. s. a & m. duro & friável & $p$ e $p$ & - \\
\hline & $2 \mathrm{Bt} 2$ & $119-185$ & $2.5 Y R 4 / 8$ & a. a & b. s. a & m. duro & firme & p e p & m. c \\
\hline & $2 \mathrm{BC}$ & $185-205$ & $2.5 Y R 4 / 8$ & f. a. a & b. s. a & m. duro & firme & pep & m. c \\
\hline \multirow[t]{4}{*}{ SXen } & Ap & $0-15$ & 10YR5/3 & a & g. i & - & Solto & $n p$ e $n p$ & - \\
\hline & $\mathrm{E}$ & $15-45$ & 10Y R 4/4 & a. $f$ & g. i & - & Solto & np e np & - \\
\hline & $2 \mathrm{Btn}$ & $45-63$ & Variegada & a. a & b. $\mathrm{s}$ & ext. duro & m. firme & $\mathrm{mp}$ e $\mathrm{mp}$ & - \\
\hline & $2 \mathrm{BCn}$ & $63-79$ & Variegada & a. $f$ & b. s. a & duro & firme & $p$ e p & - \\
\hline
\end{tabular}

(1) Variegada composta de 10YR5/4, 7.5YR5/8 e 2.5YR4/8. (2) a. f = areia franca, f. a = franco-arenoso, f. a. a =franco-argilo-arenoso, a. $a=$ argila arenosa, $a=$ areia. ${ }^{(3)}$ b. $s=$ blocos subangulares, b. $s . a=$ blocos subangulares e angulares, g. $\mathrm{i}=$ grãos individuais. ${ }^{(4)}$ np e $\mathrm{np}=$ não-plástico e não-pegajoso, Ip e Ip = ligeiramente plástico e ligeiramente pegajoso, $\mathrm{p}$ e $\mathrm{p}=$ plástico e pegajoso, $\mathrm{mp}$ e mp = muito plástico e muito pegajoso. ${ }^{(5)} \mathrm{m}$. c = moderada e comum.

Quadro 2. Atributos físicos dos perfis de Argissolo Vermelho-Amarelo eutrófico (PVAe) e de Planossolo Háplico eutrófico solódico (SXen)

\begin{tabular}{|c|c|c|c|c|c|c|c|c|c|c|}
\hline \multirow[b]{2}{*}{ Solo } & \multirow[b]{2}{*}{ Horizonte } & \multirow[b]{2}{*}{ Profundidade } & \multicolumn{8}{|c|}{ Fração granulométrica ( $\mu \mathrm{m})$} \\
\hline & & & $\begin{array}{c}\text { Areia } \\
\text { grossa } \\
\text { e média } \\
(>200)\end{array}$ & $\begin{array}{c}\text { Areia } \\
\text { fina } \\
(200-53)\end{array}$ & $\begin{array}{c}\text { Silte } \\
\text { grosso } \\
(53-20)\end{array}$ & $\begin{array}{c}\text { Silte fino } \\
(20-2)\end{array}$ & $\begin{array}{c}\text { Argila } \\
(<2)\end{array}$ & $\begin{array}{c}\text { Argila } \\
\text { natural }\end{array}$ & $\mathbf{G F}^{(1)}$ & $\begin{array}{c}\text { Relação } \\
\text { silte/argila }\end{array}$ \\
\hline \multirow[b]{2}{*}{ PVAe } & & $\mathrm{cm}$ & \multicolumn{6}{|c|}{$-\mathrm{g} \mathrm{kg}^{-1}$} & $\%$ & \\
\hline & $\begin{array}{l}\text { AB } \\
\text { BA } \\
\text { Bt1 } \\
2 B t 2 \\
2 B C\end{array}$ & $\begin{array}{c}12-43 \\
43-74 \\
74-119 \\
119-185 \\
185-205\end{array}$ & $\begin{array}{l}450 \\
520 \\
470 \\
310 \\
410\end{array}$ & $\begin{array}{l}290 \\
200 \\
230 \\
210 \\
200\end{array}$ & $\begin{array}{l}50 \\
50 \\
50 \\
80 \\
80\end{array}$ & $\begin{array}{l}30 \\
30 \\
30 \\
60 \\
60\end{array}$ & $\begin{array}{l}190 \\
190 \\
230 \\
350 \\
250\end{array}$ & $\begin{array}{r}100 \\
90 \\
110 \\
200 \\
80\end{array}$ & $\begin{array}{l}47 \\
53 \\
52 \\
43 \\
68\end{array}$ & $\begin{array}{l}0,4 \\
0,4 \\
0,4 \\
0,4 \\
0,6\end{array}$ \\
\hline SXen & $\begin{array}{l}\text { Ap } \\
\text { E } \\
2 B t n \\
2 B C n\end{array}$ & $\begin{array}{r}0-15 \\
15-45 \\
45-63 \\
63-79\end{array}$ & $\begin{array}{l}550 \\
530 \\
360 \\
710\end{array}$ & $\begin{array}{l}310 \\
280 \\
160 \\
110\end{array}$ & $\begin{array}{l}90 \\
80 \\
60 \\
20\end{array}$ & $\begin{array}{l}30 \\
30 \\
50 \\
40\end{array}$ & $\begin{array}{r}20 \\
90 \\
360 \\
120\end{array}$ & $\begin{array}{r}10 \\
50 \\
300 \\
90\end{array}$ & $\begin{array}{l}52 \\
43 \\
17 \\
25\end{array}$ & $\begin{array}{l}5,6 \\
1,3 \\
0,3 \\
0,5\end{array}$ \\
\hline
\end{tabular}

(1) Grau de floculação.

de minerais primários intemperizáveis nos dois pedons, mormente no Planossolo. Os cátions $\mathrm{Ca}^{2+} \mathrm{e}$ $\mathrm{Mg}^{2+}$ são os predominantes no complexo de troca dos dois solos, porém o teor relativamente alto de $\mathrm{Na}^{+}$ nos horizontes 2Btn e 2BCn do Planossolo, variando de 14,1 a $12,5 \%$, conferem ao mesmo o caráter solódico. O pH varia de 5,2 a 6,0, no PVAe, de 5,3 a 7,1, noSXen, refletindo, nesseúltimo, os teores mais elevados de sódio trocável, embora a reação seja ácida nos horizontes superficiais principal mente no Planossolo, condição provavel mente favor ecida pela textura superficial mais arenosa, acentuando os processos de lixiviação. O Ki é maior no SXen do que no PVAe, estando de acordo com a mineralogia das frações mais finas, condicionada pela drenagem interna, como será discutido posteriormente (Quadro 3).

\section{Mineralogia e transformações mineralógicas}

A fração areia do Argissolo apresenta maior quantidade de biotita nos horizontes mais inferiores, guardando uma relação mais estreita com a mineral ogia da rocha matriz. Por sua vez, o quartzo domina absolutamente nos horizontes mais 
Quadro 3. Atributos químicos dos perfis de Argissolo Vermelho-Amarelo (PVAe) e de Planossolo Háplico eutrófico solódico (SXen)

\begin{tabular}{|c|c|c|c|c|c|c|c|c|c|c|}
\hline \multirow{2}{*}{ Solo } & \multirow{2}{*}{ Horizonte } & \multirow{2}{*}{$\mathrm{pH}\left(\mathrm{H}_{2} \mathrm{O}\right)$} & \multicolumn{5}{|c|}{ Cátion trocável } & \multirow{2}{*}{$\mathbf{v}$} & \multirow{2}{*}{$\mathrm{Na}^{+}$} & \multirow{2}{*}{$\mathbf{K i}$} \\
\hline & & & $\mathrm{Ca}$ & Mg & K & $\mathrm{Na}$ & СТC pH 7 & & & \\
\hline & & & & & nolc & & - & 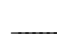 & - & \\
\hline \multirow{5}{*}{ PVAe } & $A B$ & 5,9 & 17 & 6 & 3 & 2 & 32 & 88 & 6,3 & 2,37 \\
\hline & BA & 5,6 & 20 & 6 & 4 & 2 & 36 & 89 & 5,6 & 2,26 \\
\hline & Bt1 & 5,2 & 20 & 7 & 4 & 2 & 39 & 85 & 5,1 & 2,30 \\
\hline & $2 \mathrm{Bt} 2$ & 5,8 & 23 & 9 & 3 & 2 & 43 & 86 & 4,7 & 2,29 \\
\hline & $2 B C$ & 6,0 & 18 & 11 & 2 & 2 & 38 & 87 & 5,3 & 4,20 \\
\hline \multirow[t]{4}{*}{ SXen } & Ap & 5,3 & 8 & 4 & 2 & 2 & 23 & 70 & 8,7 & 2,50 \\
\hline & E & 5,7 & 20 & 11 & 2 & 2 & 42 & 83 & 4,8 & 3,13 \\
\hline & $2 B \operatorname{tn}$ & 6,7 & 53 & 42 & 1 & 17 & 120 & 94 & 14,1 & 3,20 \\
\hline & $2 \mathrm{BCn}$ & 7,1 & 23 & 117 & 1 & 21 & 168 & 96 & 12,5 & 3,42 \\
\hline
\end{tabular}

superficiais, seguido de plagiodásios e depois biotita, indicando horizontes mais alterados (doAB aoBt1). Evidências de campo (linha de pedras) einterpretação das análises mineralógicas (teores mais el evados de quartzo na fração areia - Quadro 4) revelaram a influência de material pedimentar retrabal hado até o horizonteBt1. Na fração silte, a composição básica predominantetambém é bi otita e quartzo, seguindo a mesma tendência observada na areia. Nosiltefino, já existe a ocor rência de caulinita. Minerais opacos eincrustações de óxidos de ferro também ocorrem em quantidades di mi nutas na fração areia esilte grosso.

Os resultados encontrados para o PVAe estão de acordo com os descritos em Brasil (1973), discordando apenas na proporção de biotita que é mai or no Argissolo estudado. Da mesma forma, Ribeiro et al. (1991) e Souza et al. (1993) encontraram quartzo como o mineral predominante em perfis de PVAe no semi-árido nordestino brasileiro. I sso r eforça a afirmativa deAllen \& Fanning (1983) de que a mineralogia das frações mais grosseiras em Alfissolos e Aridissolos, principalmente nos horizontes mais inferiores, normalmente está associada com a natureza mineralógica dos diferentes materiais de origem desses solos.

O Planossolo tem nas frações mais grosseiras dos horizontes 2BCn e 2Cr (Quadro 5) dominância de biotita e hornblenda, seguido de quartzo e plagioclásios. Os dois primeiros minerais, considerados mais intemperizáveis, diminuem os seus teores do horizonte 2Cr para o 2Btn, enquanto o quartzo aumenta em direção aos horizontes mais superficiais, ondeédominante, com os maiores teores nos horizontes Ap eE, de natureza pedimentar. Por outro lado, a presença de uma linha de pedras constituída de cascal hos e, ou, cal haus de quartzo, separando os horizontes A eE dos demais, associada com a presença de hornblenda (mineral intemperizável) teores mais elevados de quartzo e maior propor ção de plagioclásios sódicos (albita) nos horizontes $\mathrm{A}$ e $\mathrm{E}$ em relação ao $2 \mathrm{Cr}$ comprovam a natureza alóctone dos horizontes superficiais. Também a hipótese de destruição de argila pela ferrólise nos horizontes superficiais pode ajudar a explicar, conjuntamente com os processos deposicionais, o alto contrastetextural no Planossolo. Segundo Brinkman (1970), a ocorrência de horizontes impermeáveis favorece a alternância de processos de oxirredução, que podem provocar a destruição dos argilominerais.

O conjunto de minerais encontrados na fração argila dos dois perfis (Quadros 4 e 5 eF iguras 2 e 3 ) difere qualitativamente em conseqüência da posição no relevo. No PVAe, que ocupa posições de topo e encosta etem mel hor drenagem, há uma constância em todo o perfil de caulinita, vermiculita e quartzo, cujos teores decrescem na ordem citada. No SXen, com drenagem imperfeita, além desses minerais, ocorrem também montmorilonita e um mineral interestratificado regular de vermiculita + mica, reconhecido pel os picos a 2,4 e 1,2 nm. No PVAe, os teores de vermi culita decrescem da base para o topo do perfil, sendo sua gênese resultante de transformações de biotitas trioctaédricas, mais abundantes nos horizontes inferiores. A caulinita, por sua vez, aumenta nesse mesmo sentido, sendo sua gênese favoreci da pelas condições de maior fluxo lixiviante e intemperismo nos horizontes mais superficiais. NoSXen, os teores de argila aumentam no sentido ascendente, ou seja, do $2 \mathrm{Cr}$ para o $2 \mathrm{Btn}$. Os horizontes Ap e E não guardam relação com a rocha subjacente, daí as suas discrepâncias mineralógicas com os demais horizontes do perfil. A montmorilonita e o mineral interestratificado também crescem seus valores do $2 \mathrm{Cr}$ para o $2 \mathrm{Btn}$, onde o teor de montmorilonita é máximo. Nesse 
Quadro 4. Componentes mineralógicos nas frações granulométricas da terra fina no perfil de Argissolo Vermelho-Amarelo eutrófico (PVe)

\begin{tabular}{|c|c|c|c|c|c|c|c|c|}
\hline \multirow{2}{*}{ Horizonte } & \multirow{2}{*}{ Profundidade } & \multirow{2}{*}{ Mineral } & \multicolumn{6}{|c|}{ Fração granulométrica ( $\mu \mathrm{m})$} \\
\hline & & & $>200$ & $200-53$ & $53-20$ & 20-2 & $<2$ & Total \\
\hline \multicolumn{3}{|c|}{$\mathrm{cm}$} & \multicolumn{6}{|c|}{$-\mathrm{g} \mathrm{kg}^{-1}$} \\
\hline \multirow[t]{2}{*}{$A B$} & $12-43$ & $\begin{array}{l}\text { Quartzo } \\
\text { Plagioclásio(1) } \\
\text { Biotita(2) }^{(2)} \\
\text { Hornblenda } \\
\text { Opacos(3) } \\
\text { Vermiculita } \\
\text { Caulinita }\end{array}$ & $\begin{array}{r}436 \\
7 \\
- \\
- \\
- \\
- \\
-\end{array}$ & $\begin{array}{r}231 \\
39 \\
7 \\
5 \\
7 \\
- \\
-\end{array}$ & $\begin{array}{r}31 \\
9 \\
6 \\
- \\
- \\
- \\
-\end{array}$ & $\begin{array}{r}15 \\
- \\
- \\
- \\
- \\
2 \\
17\end{array}$ & $\begin{array}{r}12 \\
- \\
- \\
- \\
- \\
50 \\
128\end{array}$ & $\begin{array}{r}725 \\
55 \\
13 \\
5 \\
7 \\
52 \\
145\end{array}$ \\
\hline & & Total & 443 & 289 & 46 & 34 & 190 & 1.002 \\
\hline \multirow[t]{2}{*}{ BA } & $43-74$ & $\begin{array}{l}\text { Quartzo } \\
\text { Plagooclásio } \\
\text { Biotita } \\
\text { Hornblenda } \\
\text { Opacos } \\
\text { Vermiculita } \\
\text { Caulinita }\end{array}$ & $\begin{array}{r}505 \\
15 \\
- \\
- \\
11 \\
- \\
-\end{array}$ & $\begin{array}{r}163 \\
30 \\
- \\
- \\
5 \\
- \\
-\end{array}$ & $\begin{array}{r}24 \\
10 \\
17 \\
- \\
2 \\
- \\
-\end{array}$ & $\begin{array}{r}14 \\
6 \\
- \\
- \\
- \\
- \\
9\end{array}$ & $\begin{array}{r}16 \\
- \\
- \\
- \\
- \\
62 \\
112\end{array}$ & $\begin{array}{r}722 \\
61 \\
17 \\
- \\
18 \\
62 \\
121\end{array}$ \\
\hline & & Total & 531 & 198 & 53 & 29 & 190 & 1.001 \\
\hline \multirow[t]{2}{*}{ Bt1 } & 74-119 & $\begin{array}{l}\text { Quartzo } \\
\text { Plagioclásio } \\
\text { Biotita } \\
\text { Hornblenda } \\
\text { Opacos } \\
\text { Vermiculita } \\
\text { Caulinita }\end{array}$ & $\begin{array}{r}399 \\
24 \\
13 \\
3 \\
3 \\
- \\
-\end{array}$ & $\begin{array}{r}194 \\
23 \\
10 \\
- \\
- \\
- \\
-\end{array}$ & $\begin{array}{r}21 \\
13 \\
17 \\
- \\
2 \\
- \\
-\end{array}$ & $\begin{array}{r}11 \\
7 \\
- \\
- \\
- \\
- \\
12\end{array}$ & $\begin{array}{r}21 \\
- \\
- \\
- \\
- \\
65 \\
144\end{array}$ & $\begin{array}{r}646 \\
67 \\
40 \\
3 \\
5 \\
65 \\
156\end{array}$ \\
\hline & & Total & 442 & 227 & 53 & 30 & 230 & $982^{(4)}$ \\
\hline \multirow[t]{2}{*}{$2 \mathrm{Bt} 2$} & $119-185$ & $\begin{array}{l}\text { Quartzo } \\
\text { Plagioclásio } \\
\text { Biotita } \\
\text { Hornblenda } \\
\text { Opacos } \\
\text { Vermiculita } \\
\text { Caulinita }\end{array}$ & $\begin{array}{r}180 \\
13 \\
71 \\
- \\
- \\
- \\
-\end{array}$ & $\begin{array}{r}119 \\
18 \\
73 \\
- \\
- \\
- \\
-\end{array}$ & $\begin{array}{r}14 \\
5 \\
62 \\
- \\
- \\
- \\
-\end{array}$ & $\begin{array}{r}9 \\
6 \\
- \\
- \\
- \\
- \\
42\end{array}$ & $\begin{array}{r}15 \\
- \\
- \\
- \\
- \\
102 \\
233\end{array}$ & $\begin{array}{r}337 \\
42 \\
206 \\
- \\
- \\
102 \\
275\end{array}$ \\
\hline & & Total & 264 & 210 & 81 & 57 & 350 & 962 \\
\hline \multirow[t]{2}{*}{ 2BC } & $185-205+$ & $\begin{array}{l}\text { Quartzo } \\
\text { Plagioclásio } \\
\text { Biotita } \\
\text { Hornblenda } \\
\text { Opacos } \\
\text { Vermiculita } \\
\text { Caulinita }\end{array}$ & $\begin{array}{r}170 \\
12 \\
210 \\
- \\
10 \\
- \\
-\end{array}$ & $\begin{array}{r}88 \\
12 \\
100 \\
- \\
- \\
- \\
-\end{array}$ & $\begin{array}{r}3 \\
\overline{7} \\
- \\
- \\
- \\
-\end{array}$ & $\begin{array}{r}8 \\
5 \\
- \\
- \\
- \\
7 \\
41\end{array}$ & $\begin{array}{r}14 \\
- \\
- \\
- \\
- \\
152 \\
84\end{array}$ & $\begin{array}{r}283 \\
29 \\
386 \\
- \\
10 \\
159 \\
125\end{array}$ \\
\hline & & Total & 402 & 200 & 79 & 61 & 250 & 992 \\
\hline
\end{tabular}

(1) Predominantemente albita. ${ }^{(2)}$ Preponderantemente flogopita-biotita trioctaédrica. ${ }^{(3)}$ Óxidos de ferro; ${ }^{(4)} \mathrm{A}$ diferença para 1.000 está associada a minerais pesados e indeterminados.

último horizonte, porém, não foi mais detectado o mineral interestratificado que possivelmente se alterou para montmorilonita e, ou, caulinita.

Conforme ficou evidenciado, foram encontrados nos dois perfis, minerais defácil intemperização nas frações areia esilte, por serem os sol os rel ativamente pouco intemperizados. A mineralogia da fração argila, por outro lado, é perfeitamente compatível com as diferenças químicas constatadas nos dois solos, ou seja, a maior soma de bases e maior atividade da argila do SXen estariam relacionadas com a presença de montmorilonita, enquanto a maior pobreza em bases e a menor CTC do PVAe estariam relacionadas com a maior presença de caulinita e com a intercal ação da vermiculita com polímeros de hidróxi-Al nas entrecamadas, o que reduz consideravelmente a CTC efetiva deste argilomineral (Douglas, 1977). 
Quadro 5. Componentes mineralógicos nas frações granulométricas da terra fina no perfil de Planossolo Háplico eutrófico solódico (SXen)

\begin{tabular}{|c|c|c|c|c|c|c|c|c|}
\hline \multirow{2}{*}{ Horizonte } & \multirow{2}{*}{ Profundidade } & \multirow{2}{*}{ Mineral } & \multicolumn{6}{|c|}{ Fração granulométrica $(\mu \mathrm{m})$} \\
\hline & & & $>200$ & $200-53$ & 53-20 & $20-2$ & $<2$ & Total \\
\hline \multicolumn{3}{|c|}{$\mathrm{cm}$} & \multicolumn{6}{|c|}{$\mathrm{g} \mathrm{kg}^{-1}$} \\
\hline \multirow[t]{2}{*}{ Ap } & $0-15$ & $\begin{array}{l}\text { Quartzo } \\
\text { Plagioclásio(1) } \\
\text { Biotital(2) } \\
\text { Hornblenda } \\
\text { Opacos(3) } \\
\text { Ilita } \\
\text { Caulinita } \\
\text { Vermiculita } \\
\text { Min. Int 2,4 } \text { nm(4) }^{(4)}\end{array}$ & $\begin{array}{r}480 \\
28 \\
28 \\
4 \\
- \\
- \\
-\end{array}$ & $\begin{array}{r}254 \\
34 \\
13 \\
5 \\
4 \\
- \\
- \\
- \\
-\end{array}$ & $\begin{array}{r}40 \\
25 \\
17 \\
\overline{2} \\
- \\
- \\
-\end{array}$ & $\begin{array}{r}7 \\
- \\
- \\
\overline{1} \\
12 \\
-\end{array}$ & $\begin{array}{r}1 \\
- \\
- \\
- \\
- \\
13 \\
2 \\
6\end{array}$ & $\begin{array}{r}782 \\
87 \\
30 \\
33 \\
10 \\
1 \\
25 \\
2 \\
6\end{array}$ \\
\hline & & Total & 540 & 310 & 84 & 20 & 22 & $976(5)$ \\
\hline \multirow[t]{2}{*}{ E } & $15-45$ & $\begin{array}{l}\text { Quartzo } \\
\text { Plagioclásio } \\
\text { Biotita } \\
\text { Hornblenda } \\
\text { Opacos } \\
\text { Ilita } \\
\text { Caulinita } \\
\text { Min. Int 2,4 nm }\end{array}$ & $\begin{array}{r}440 \\
63 \\
27 \\
- \\
- \\
- \\
-\end{array}$ & $\begin{array}{r}181 \\
30 \\
54 \\
6 \\
9 \\
- \\
- \\
-\end{array}$ & $\begin{array}{r}51 \\
24 \\
5 \\
1 \\
2 \\
- \\
- \\
-\end{array}$ & $\begin{array}{r}13 \\
- \\
- \\
- \\
- \\
3 \\
8 \\
8\end{array}$ & $\begin{array}{r}9 \\
- \\
- \\
- \\
- \\
70 \\
9\end{array}$ & $\begin{array}{r}694 \\
117 \\
59 \\
34 \\
11 \\
3 \\
78 \\
17\end{array}$ \\
\hline & & Total & 530 & 280 & 83 & 32 & 88 & 1013 \\
\hline \multirow[t]{2}{*}{$2 \mathrm{Btn}$} & $45-63$ & $\begin{array}{l}\text { Quartzo } \\
\text { Plagioclásio } \\
\text { Biotita } \\
\text { Hornblenda } \\
\text { Opacos } \\
\text { Caulinita } \\
\text { Montmorilonita }\end{array}$ & $\begin{array}{r}285 \\
36 \\
3 \\
36 \\
- \\
- \\
-\end{array}$ & $\begin{array}{r}117 \\
7 \\
19 \\
17 \\
2 \\
- \\
-\end{array}$ & $\begin{array}{r}30 \\
19 \\
12 \\
- \\
- \\
-\end{array}$ & $\begin{array}{r}17 \\
- \\
- \\
- \\
- \\
14 \\
17\end{array}$ & $\begin{array}{r}36 \\
- \\
- \\
- \\
180 \\
144\end{array}$ & $\begin{array}{r}485 \\
62 \\
34 \\
53 \\
2 \\
194 \\
161\end{array}$ \\
\hline & & Total & 360 & 162 & 61 & 48 & 360 & 991 \\
\hline \multirow[t]{2}{*}{$2 \mathrm{BCn}$} & $63-79$ & $\begin{array}{l}\text { Quartzo } \\
\text { Plagioclásio } \\
\text { Biotita } \\
\text { Hornblenda } \\
\text { Opacos } \\
\text { Ilita } \\
\text { Caulinita } \\
\text { Montmorilonita } \\
\text { Min. Int 2,4 nm }\end{array}$ & $\begin{array}{r}9 \\
613 \\
88 \\
- \\
- \\
- \\
-\end{array}$ & $\begin{array}{r}14 \\
1 \\
65 \\
29 \\
3 \\
- \\
- \\
-\end{array}$ & $\begin{array}{r}1 \\
19 \\
2 \\
- \\
- \\
- \\
-\end{array}$ & $\begin{array}{r}2 \\
- \\
8 \\
- \\
2 \\
8 \\
10 \\
10\end{array}$ & $\begin{array}{r}- \\
- \\
- \\
- \\
- \\
66 \\
30 \\
24\end{array}$ & $\begin{array}{r}26 \\
1 \\
697 \\
127 \\
3 \\
2 \\
74 \\
40 \\
34\end{array}$ \\
\hline & & Total & 710 & 112 & 22 & 40 & 120 & 1004 \\
\hline \multirow[t]{2}{*}{$2 \mathrm{Cr}$} & $79-170+$ & $\begin{array}{l}\text { Quartzo } \\
\text { Plagioclásio } \\
\text { Biotita } \\
\text { Hornblenda } \\
\text { Opacos } \\
\text { Ilita } \\
\text { Caulinita } \\
\text { Montmorilonita } \\
\text { Min. Int. 2,4 nm }\end{array}$ & $\begin{array}{r}19 \\
7 \\
473 \\
280 \\
- \\
- \\
- \\
- \\
-\end{array}$ & $\begin{array}{r}- \\
12 \overline{-} \\
15 \\
2 \\
- \\
- \\
-\end{array}$ & $\begin{array}{r}- \\
23 \\
2 \\
- \\
- \\
- \\
- \\
-\end{array}$ & $\begin{array}{l}4 \\
- \\
- \\
4 \\
- \\
- \\
1 \\
- \\
4\end{array}$ & $\begin{array}{r}- \\
- \\
- \\
- \\
5 \\
3 \\
13 \\
18 \\
4\end{array}$ & $\begin{array}{r}23 \\
7 \\
620 \\
301 \\
2 \\
3 \\
14 \\
18 \\
8\end{array}$ \\
\hline & & Total & 779 & 141 & 25 & 13 & 38 & 996 \\
\hline
\end{tabular}

(1) Predominantemente al bita. ${ }^{(2)}$ Preponderantemente flogopita-biotita trioctaédrica. ${ }^{(3)}$ Óxido de ferro. ${ }^{(4)}$ I nterestratificação regular de vermiculita + mica. ${ }^{(5)}$ A diferença para 1.000 está associada a minerais pesados e indeterminados.

Os dois solos (PVAe e SXen) localizam-se na mesma zona fisiográfica, estando sujeitos às mesmas condições de clima (regime hídricoústico transicional para arídico), litologia e vegetação regional (caatinga hiperxerófila). A maior diferença relaciona-se com a drenagem interna. O SXen, graças à sua posição no relevo, sofre menor lixiviação e apresenta enriquecimento de cátions eânions provenientes das partes mais altas da toposseqüência. Tudo isso contribui para o aumento na soma de bases, \% de sódi o trocável e Ki, cujos valores são mais al tos que no PVAe. 


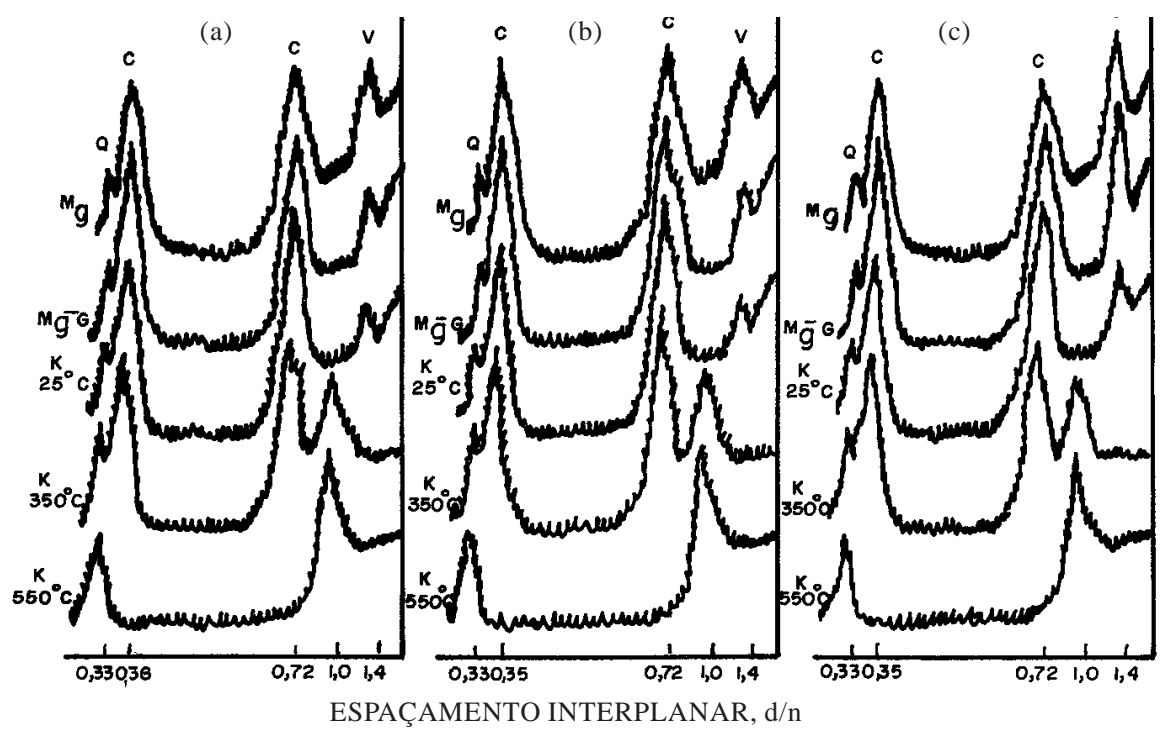

Figura 2. Difratogramas da fração argila do perfil 2 (PVAe). (a) horizonte AB; (b) horizonte 2Bt2e (c) horizonte 2BC. Q: quartzo; C: caulinita; V: vermiculita.Valores de d/n em nanômetros.

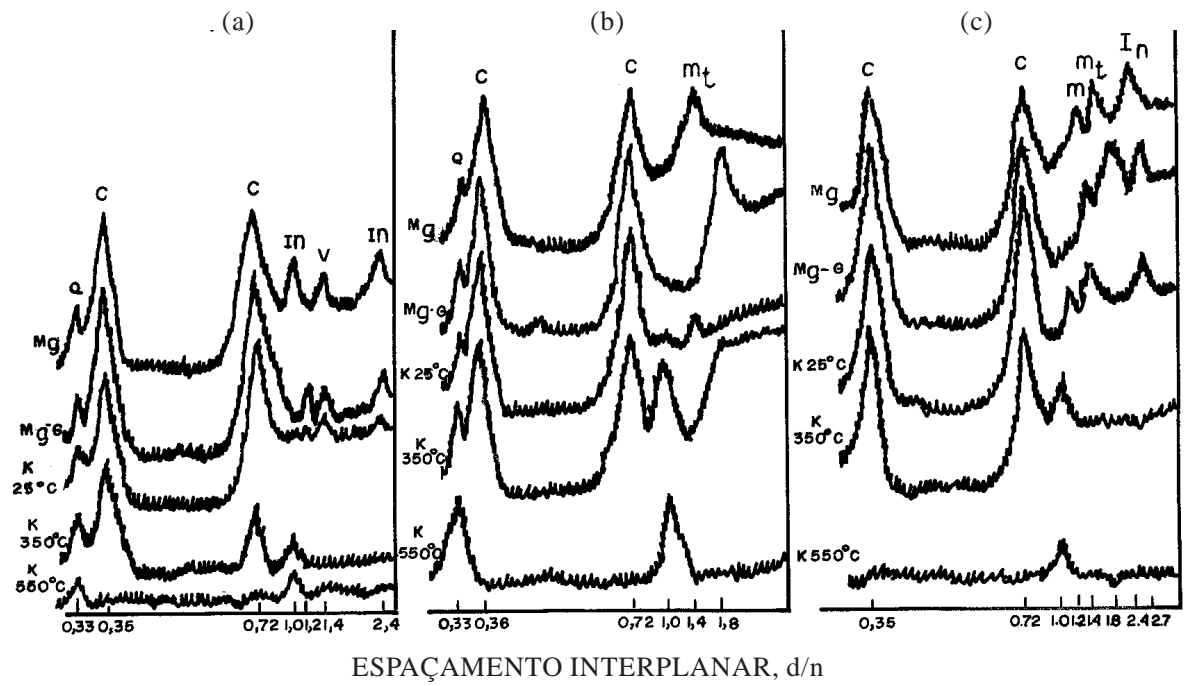

Figura 3. Difratogramas da fração argila do perfil 9 (SXen). (a) horizonte Ap; (b) horizonte 2Btn e (c) horizonte 2Cr2. Q: quartzo; C: caulinita; V: vermiculita;In: interestratificado; Mt: montmorilonita. Valores de d/n em nanômetros.

A gênese dos argi lominerais foi, portanto, afetada marcadamente pelas condições internas de drenagem dos solos. A formação e a preservação de montmorilonita no Planossolo estão diretamente associadas à sua condição de drenagem impedida (Borchardt, 1977), fato esse que contribui para maior atividade de silício e bases no sistema e maior atividade da argila nesse solo. A hornblenda pode também sealterar diretamente para montmorilonita em condições de menor fluxo lixiviante (Besoain, 1985). A ocorrência do mineral interestratificado pode está associada com alterações incipientes da biotita.
No Argissolo, a presença de vermiculita resulta da transformação da bi otita encontrada em grande quantidade no horizonte mais inferior, concordando com a afirmativa de Douglas (1977) de que este mineral forma-se quase semprea partir da alteração de mica. O aumento de caulinita da base para o topo nos dois perfis pode indicar a intemperização de vermiculita ou montmorilonita formando caulinita, visto que o intemperismo aumenta de intensidade em direção à superfície do solo. U ma eluviação preferencial de montmorilonita ou vermiculita em relação à caulinita também não pode ser descartada (Luz et al., 1992). 
As figuras 4, 5 e 6 apresentam processos de alteração de minerais noSXen obtidos por microscopia el etrônica de varredura. Esta ferramenta tem sido utilizada com o propósito de fornecer informações complementares ou elucidar dúvidas que não podem ser facilmente obtidas com a microscopia ótica convencional e com a difração de raios-X (Eswaran, 1979; Berner \& Schott, 1982; Eswaran \& Shoba, 1983; Keller \& Balasubramaniam, 1989; Miklos et al., 1996). A figura 4 mostra fotomicrografias da fração siltefino no horizonte $2 \mathrm{Cr}$, onde seobserva claramente vermiculita originada pela intemperização da biotita, bem como a estrutura em camadas formada no novo mineral. A figura 5 exibe pseudomorfoses de vermiculita alterada da biotita para caulinita no horizonte 2Btn. Esses agregados de cristais de caulinita, notamanho da argila, representam, assim, uma boa contribuição para a formação da argila "in situ" nesse horizonte. A figura 6 mostra pseudomorfoses de montmorilonita para caulinita também no horizonte 2Btn, as quais contêm, igual mente, cristais de caulinita no tamanho da argila fina.

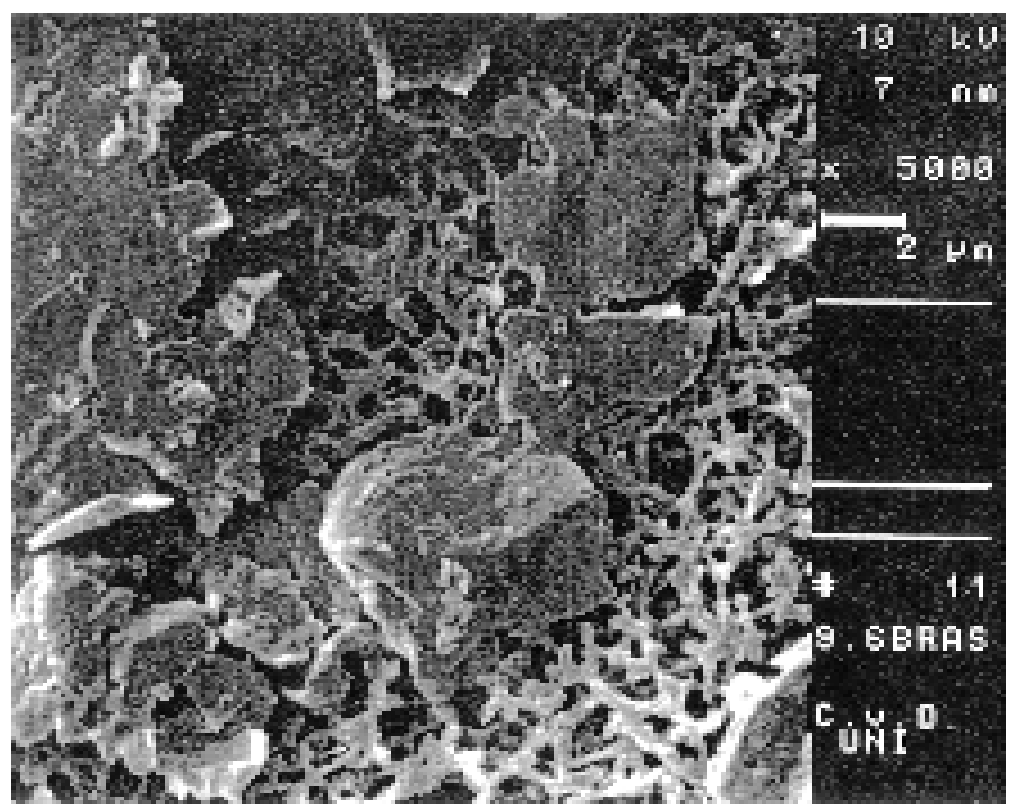

Figura 4. Fotografia obtida por microscopia eletrônica de varredura, mostrando vermiculita intemperizada da biotita, no horizonte $2 \mathrm{Cr}$ do perfil 9 (SXen).

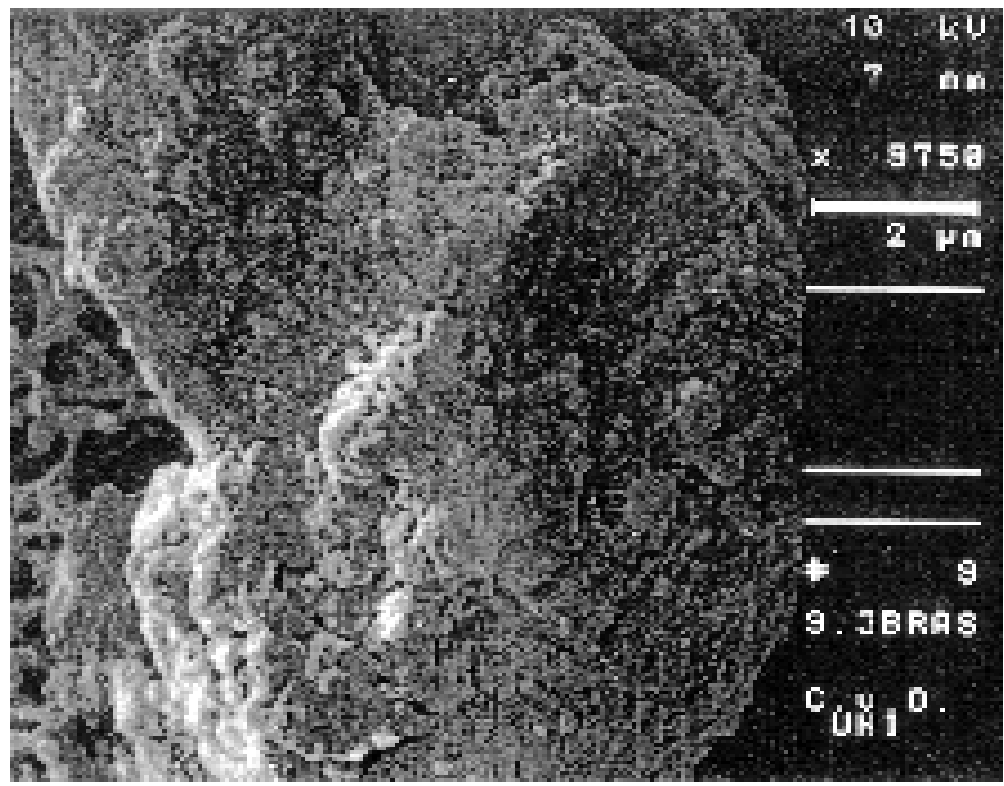

Figura 5. Fotografia obtida por microscopia eletrônica de varredura, mostrando pseudomorfoses de vermiculita intemperizada da biotita, para caulinita, no horizonte 2Btn do perfil 9 (SXen). 


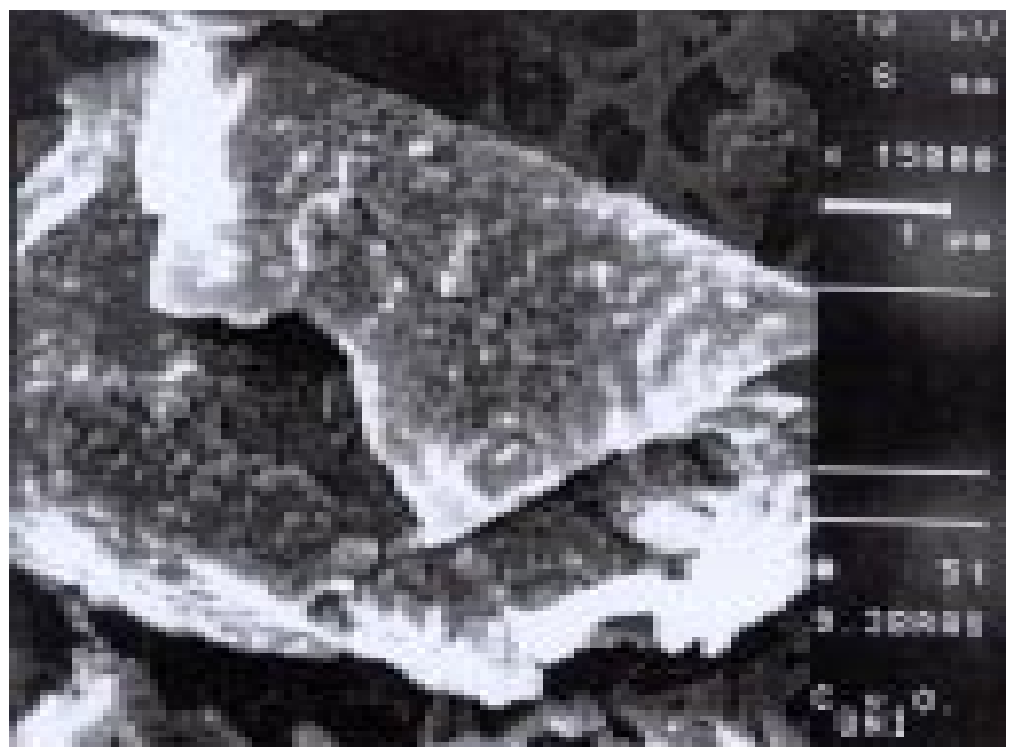

Figura 6. Fotografia obtida por microscopia eletrônica de varredura, mostrando pseudomorfoses de montmorilonita, para caulinita, no horizonte 2Btn do perfil 9 (SXen).

\section{CONCLUSÕES}

1. A mineralogia da fração argila é constituída predominantemente de caulinita e vermiculita no Argissolo e de caulinita e montmorilonita no Planossolo, ocorrendo também nesse último a presença de um mineral interestratificado regular de mica + vermiculita. Tais diferenças de mineralogia resultam essencial mente da diferença de drenagem interna entre os dois solos, resultante de suas posições na toposseqüência.

2. A presença dos minerais alteráveis (biotita, hornblenda e plagioclásios) nas frações mais grosseiras dos dois perfis indica pequeno grau de intemperismo e, ou, maturidade dos solos.

3. Nos dois perfis estudados, omai or teor de argila do horizonte B textural resulta, sugestivamente, da alteração dos minerais primários decomponíveis, presentes na rocha subjacente.

4. Em ambos os perfis, a presença de linha de pedras, associada com a geomorfologia da região e com as diferenças mineralógicas, observadas entre os horizontes mais superficiais e os mais inferiores, sugere uma duplicidade de materiais originários na gênese desses solos.

5. Os teores elevados de sódio observados no Planossol o são resultantes da decomposição da al bita e de outros plagioclásios ricos em sódio, associado com o clima semi-árido e a drenagem deficiente do sol o.

6. São sugeridas as seguintes seqüências de alteração: Argissolo - Biotita $\Rightarrow$ vermiculita $\Rightarrow$ caulinita e plagioclásios $\Rightarrow$ caulinita Planossolo Biotita $\Rightarrow$ ilita $\Rightarrow$ interestratificado $\Rightarrow$ vermiculita $\Rightarrow$ montmorilonita $\Rightarrow$ caulinita e hornblenda $\Rightarrow$ montmorilonita $\Rightarrow$ caulinita.
7. Nos dois perfis a, caulinita é o mineral mais estável das seqüências de alteração.

\section{LITERATURA CITADA}

ALLEN, B.L. \& FANNING, D.S. Composition and soil genesis. In: WILDUNG, L.P.; SMECK, N.E. \& HALL, G.F., eds. Pedogenesis and Soil Taxonomy. I. Concepts and interactions. Amsterdam, Elsevier, 1983. p.141-192.

BERNER, R.A. \& SCHOTT, J. Mechanism of pyroxene and amphibole weathering. II. Observations of soil grains. Am. J. Soil Sci., 282:1214-1231, 1982

BESOAIN, E. Mineralogia de arcillas de suelos. San J osé, Costa Rica, IICA, 1985. 1216p.

BORCHARDT, G.A. Montmorillonite and others smectite minerals. In: DIXON, J.B. \& WEED, S.B., eds. Minerals in soil environments. Madison, Soil Science Society of America, 1977, p.293-330.

BRASIL. Ministério da Agricultura. Divisão de Pesquisa Pedológica, DNPEA. Levantamento exploratórioreconhecimento de solos do estado do Ceará. Recife, Convênios MA/DNPEA - SUDENE/DRN, MA/CONTAP/ USAID/ETA, 1973. v.1-2, 502p. (Boletim Técnico, 28)

BRINDLEY, G.W. I dentification of clay minerals by X-ray diffraction analysis. In: National Conference on Clays and Clay Tecnology, 1th. Proceedings. San Francisco, Department of National Resources, 1955. p.119-129.

BRINKMAN, R. Ferrolysis, a hydromorphic soil forming process. Geoderma, 3:199-206, 1970.

BROWN, G. The X-ray identification and crystal structures of clay minerals. London, Mineralogical Society, 1961. 544p.

CAMARGO, M.N.; KLAMT, E. \& KAUFFMAN, J.H. Sistema brasileiro de dassificação de sol os. B. Inf. SBCS, 12:11-33, 1987. 
CASS, A. \& J OHNSTON, M.A. Physical and clay mineralogical properties of some Natal and Eastern Transvaal soils. South Afr. J. Plant. Soil, 2:79-84, 1985

DEMATTÊ, J.L.I \& MARCONI,A. A drenagem na mineralogia de solos desenvolvidos de diabásio em Piracicaba, SP. R. Bras. Ci. Solo, 15:1-8, 1991

DEMATTÊ, J.L.I.; MARCONI, A.; SPAROVEK, G. \& VIDAL TORRADO, P. Estimativa da evolução do intemperismo mediante ganhos e perdas de íons numa seqüência de sol os desenvolvidos de diabásio e influenciados pela drenagem em Piracicaba, SP. R. Bras. Ci. Solo, 15:69-73, 1991.

DOUGLAS, L.A. Vermiculites. In: DIXON, J .B. \& WEED, S.B., eds. Minerals in soil environments. Wisconsin, Soil Science Society of America, 1977. p.259-288.

ESWARAN, H. \& SHOBA, S.A. Scanning microscopy in soil research. In: BULLOCK, P. \& MURPHY, C.P., eds. Soil micromorphology. Melbourne, Academy Publishing, 1983. v.4, 356p.

ESWARAN, $\mathrm{H}$. The alteration of plagiodlases and augites under differing pedo-environmental conditions. J. Soil Sci., 30:547-555, 1979.

EMPRESA BRASILEIRA DE PESQUISA AGROPEUÁRIA EMBRAPA. Serviço Nacional de Levantamento e Conservação de Solos. Manual de métodos de análises de solos. Rio de janeiro, 1979. não paginado.

EMPRESA BRASILEIRA DE PESQUISA AGROPEUÁRIA EMBRAPA. Serviço Nacional de Levantamento e Conservação de Solos. Definição e notação de horizontes e camadas do solo. 2.ed. Rio de janeiro, 1988. 54p.

EMPRESA BRASILEIRA DE PESQUISA AGROPEUÁRIA EMBRAPA. Serviço Nacional de Levantamento e Conservação de Solos. Sistema brasileiro de classificação de solos. Rio de J aneiro, 1999. 412p.

GEBHARDT, H.; MEYER, B. \& SCHEFFER, F. Mineralogische schnelluntersuchung der grobton schluff und fein sandfraktionen von boden mit dem phasenkontrastmikroskop. Zeiss Mitteil., 4:309-322, 1967.

J ACKSON, M.L. Soil chemical analysis: Advanced course. 2.ed. Madison, University of Wisconsin, 1969. 895p.

J OHNS, W.D.; GRIM, R.E. \& BRADLEY, W.F. Quantitative estimation of day minerals by diffraction methods. J. Sed. Petr. 24:242-251, 1954.
KELLER, W.D. \& BALASUBRAMANIAM, K.S. Scanning electron micrographs of clay minerals formed by weathering and other genetic processes. In: WEATHERING its products and deposits, processes. Athens, Theophrastus Publications, 1989. v.1, 462p.

LEMOS, R.C. \& SANTOS, R.D. Manual de descrição e col eta do solo no campo. Campinas, Sociedade Brasileira de Ciência do Solo, 1984. 46p.

LUZ, L.R.Q.P.; SANTOS, M.C.D. \& MERMUT, A.R. Pedogênese em uma toposseqüência do semi-árido de Pernambuco. R. Bras. Ci. Solo, 16:95-102, 1992.

MIKLOS, A.A.W.; TELLES, E.C.C. \& MARIANO, B.H.B Contribuições da microscopia el etrônica de varredura no estudo da gênese de argilo-minerais. In: CONGRESSO LATINO AMERICANO DE CIÊNCIA DO SOLO, 13., Águas de Lindóia, 1996. Solo-suelo 96. Trabalhos. Piracicaba, Sociedade Brasileira de Ciência do Solo, 1996. CD ROM.

MOREIRA, E.G.S. Caracterização e gênese de três pedons de Sol onetz solodizado do sertão central e médio J aguaribe Estado do Ceará. Piracicaba, Escola Superior de Agricultura "Luiz de Queiroz", 1979. 83p. (Tese de Doutorado)

OLIVEIRA,J .B.; ACOMINE, P.K.T. \& CAMARGO, M.N. Classes gerais de solos do Brasil: guia auxiliar para seu reconhecimento. J aboticabal, FUNEP, 1992. 201p.

RIBEIRO, M.R.; SANTOS, M.C.D.; \& FERREIRA, M.G.V.X. Caracterização e gênese de Podzólicos Vermel ho-Amarel os do sertão de Pernambuco. R. Bras. Ci. Solo, 15:75-81, 1991.

SOIL SURVEY STAFF. Keys to soil taxonomy, 5.ed. Washington, SMSS Technical Monograph USDA-SCS, 1992. 541p.

SOUZA, E.A.; RIBEIRO, M.R. \& FERREIRA, M.G.V.X. Caracterização e gênese de solos do baixio de I recê-Bahia R. Bras. Ci. Solo, 17:89-97, 1993.

SOUZA, M.J.N. Geomorfologia do vale do Choró-Ceará. São Paulo, Instituto de Geografia-USP, 1975. 212p. (Tese de Doutorado)

TROGER, W.E. Optische bestimmung der gesteinsbildenden minerale, teile 1 und 2. Stuttgart, Schweizerbartsche verlagsbuchhandlung, 1969. 188p. 